\title{
Bacterial Persistence
}

\author{
Methods and Protocols
}

\author{
Second Edition
}

Edited by

\section{Natalie Verstraeten and Jan Michiels \\ VIB-KU Leuven Center for Microbiology, VIB, Leuven, Belgium; \\ Centre of Microbial and Plant Genetics, KU Leuven, Leuven, Belgium}




\title{
Chapter 16
}

\section{In Vitro Models for the Study of the Intracellular Activity of Antibiotics}

\author{
Frédéric Peyrusson, Tiep K. Nguyen, Julien M. Buyck @, Sandrine Lemaire, \\ Gang Wang, Cristina Seral, Paul M. Tulkens $\mathbb{D}^{\circ}$, and Françoise Van Bambeke $\mathbb{e}$
}

\begin{abstract}
Intracellular bacteria are poorly responsive to antibiotic treatment. Pharmacological studies are thus needed to determine the antibiotics which are the most potent or effective against intracellular bacteria as well as to explore the reasons for poor bacterial responsiveness. An in vitro pharmacodynamic model is described, consisting of (1) phagocytosis of preopsonized bacteria by eukaryotic cells, (2) elimination of noninternalized bacteria with gentamicin, (3) incubation of infected cells with antibiotics, and (4) determination of surviving bacteria by viable cell counting and normalization of the counts based on sample protein content. The use of strains expressing fluorescent proteins under the control of an inducible promoter allows to follow intracellular bacterial division at the individual level and therefore to monitor bacterial persisters that do not multiply anymore.
\end{abstract}

Key words Intracellular infection, Gentamicin, Antibiotic, Phagocytosis, Opsonization, Pharmacodynamics, Efficacy, Relative potency

\section{Introduction}

Intracellular survival of bacteria is now recognized as a major factor associated with dissemination, persistence, or recurrence of infections [1-7]. When residing inside eukaryotic cells, bacteria are indeed protected from the host humoral immune defenses and often adopt a dormant lifestyle less responsive to antibiotic action. Studies conducted over the last 10 years suggest that these dormant bacteria may correspond to bacterial persisters $[8,9]$. Moreover, in order to exert their activity against intracellular bacteria, antibiotics have to gain access to the infected compartment within the cells and to express their activity in this specific environment $[10,11]$. For these reasons, intracellular activity of antibiotics is unpredictable based on the simple evaluation of their activity against extracellular bacteria in broth and of their accumulation within eukaryotic cells.

Natalie Verstraeten and Jan Michiels (eds.), Bacterial Persistence: Methods and Protocols, Methods in Molecular Biology, vol. 2357, https://doi.org/10.1007/978-1-0716-1621-5_16,

(C) The Author(s), under exclusive license to Springer Science+Business Media, LLC, part of Springer Nature 2021 
Appropriate models need to be developed for the correct assessment of the capacity of antibiotics to act upon intracellular bacteria.

We present here an in vitro model which allows studying the pharmacodynamics of antibiotics against intracellular bacteria. This model is highly flexible, being adaptable to several bacterial species or strains [12-15] as well as to many cell types [14, 16-18]. It has been used to compare the activity of commercially available antibiotics $[12,19]$ and of molecules in preclinical or clinical development (most of which are now registered or in the late phases in clinical trials $[14,16,19-26])$, with the aim of predicting their potential interest for the treatment of persistent infections. In the case of Staphylococcus aureus infections, it has been validated vs. animal models of intracellular infection $[27,28]$.

\section{Materials}

\subsection{Equipment}

1. Laminar flow hood: Work is performed in a laminar flow hood in a room with biosafety level adapted to the pathogenicity of the microorganism under investigation [29].

2. $\mathrm{CO}_{2}$ incubator.

3. Bacteriology incubator.

4. Hemocytometer.

5. Spectrophotometer.

\subsection{Reagents}

1. Culture medium adapted for eukaryotic cell line use: Usually RPMI-1640 or DMEM, supplemented with 10\% fetal calf serum.

2. Cation-adjusted Mueller-Hinton Broth (CA-MHB) and tryptic soy agar plates (TSA) (or any other specific medium more adapted to the bacterial species investigated).

3. Sterile distilled water.

4. Sterile phosphate buffer saline (PBS): $8 \mathrm{~g} \mathrm{NaCl}, 0.2 \mathrm{~g} \mathrm{KCl}$, $1.44 \mathrm{~g} \mathrm{Na}_{2} \mathrm{HPO}_{4}, 0.24 \mathrm{~g} \mathrm{KH}_{2} \mathrm{PO}_{4}, \mathrm{l} \mathrm{L}$ distilled water. Adjust to $\mathrm{pH} 7.4$.

5. Human serum from healthy volunteers (for bacterial opsonization).

6. $40 \mathrm{mg} / \mathrm{mL}$ gentamicin stock solution.

7. Stock solution of the antibiotic under study.

8. Reagents (see Note 1) or kit (several kits are commercially available) for protein assay according to the Folin-Ciocalteu method, also referred to as Lowry's method [30].

9. Reagents (see Note 2 ) or kit for cell viability assay (e.g., trypan blue exclusion assay [31], or release of the cytosolic enzyme lactate dehydrogenase (LDH) [32]). 


\section{Methods}

The method described is illustrated in Fig. 1.

\subsection{Preparation of Bacterial Suspension and of Media}

\subsection{Opsonization of Bacteria}

1. The day before the experiment, prepare an overnight bacterial culture in $15 \mathrm{~mL}$ of $\mathrm{MHB}\left(37^{\circ} \mathrm{C}\right.$; agitation) to obtain a stationary-phase culture.

2. Unfreeze human serum.

3. Prewarm culture medium, sterile water, and PBS at $37^{\circ} \mathrm{C}$.

Opsonization is a process by which bacteria are marked by opsonins, which are serum proteins (like antibodies or complement proteins) bridging bacteria to the cell surface in order to favor phagocytosis ( see Note 3 ).

1. Centrifuge the overnight culture to pellet bacteria $(7 \mathrm{~min}$ at $3200 \times g)$.

2. Resuspend in $1 \mathrm{~mL}$ of human serum; dilute with $9 \mathrm{~mL}$ of eukaryotic cell culture medium (not supplemented with fetal calf serum in this case, since human serum at a final concentration of $10 \%$ is present). Do not vortex.

3. Incubate for $30-60 \mathrm{~min}$ at $37{ }^{\circ} \mathrm{C}$ under gentle agitation $(130 \mathrm{rpm})[12,33]$.
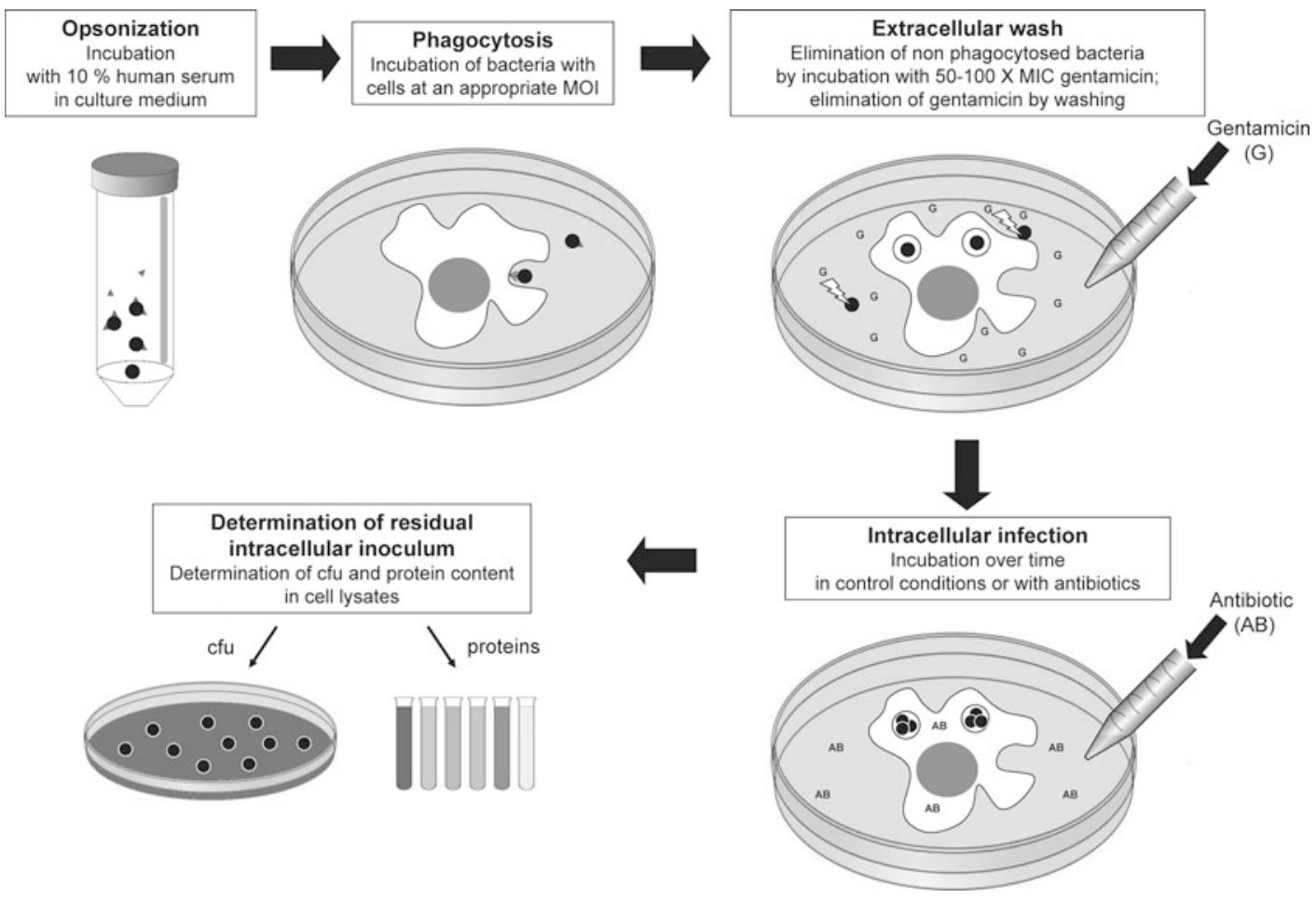

Fig. 1 In vitro model for the assessment of intracellular activity of antibiotics 


\subsection{Preparation of Eukaryotic Cells and Bacteria for Infection}

\subsection{Phagocytosis}

1. If using eukaryotic cells in suspension, count them (for example using a hemocytometer) in order to obtain a density of 500,000-750,000 cells/mL (see Note 4).

2. If using adherent cells, plate them in multiwell plates. They should have reached $80 \%$ confluence at the time of the experiment. Prepare extra wells to be used for cell counting at the time of the infection.

3. Centrifuge opsonized bacteria for $7 \mathrm{~min}$ at $3200 \times g$ and remove supernatant. Resuspend the pellet in $2 \mathrm{~mL}$ of PBS or culture medium and calculate the bacterial concentration, based on a calibration curve establishing the correlation between colony forming unit (CFU) counts and $\mathrm{OD}_{620 \mathrm{~nm}}$ or on the turbidity of the bacterial suspension (McFarland).

This step is critical, in the sense that it is specific for each bacterial strain or species $[12,13,19,33,34]$ and for the cell type to use for infection $[14,16,17,21]$ and should be adapted by the experimenter (Fig. 2). The objective is to obtain after phagocytosis an intracellular inoculum that is high enough to allow further growth of the bacteria but low enough to avoid killing the host cells (typically $10^{6} \mathrm{CFU} / \mathrm{mg}$ cell protein). The general principle of this part of the protocol is explained hereafter.

1. Phagocytosis: Add bacterial suspension to cell suspension or to adherent cells in order to obtain the desired multiplicity of infection (MOI; number of bacteria/cell); when setting up the model, use in parallel different MOI (typically $1: 1 ; 5: 1$; $10: 1 ; 20: 1 ; 50: 1)$. Incubate at $37{ }^{\circ} \mathrm{C}$ in a $\mathrm{CO}_{2}$ incubator for appropriate times; when setting up the model, compare different incubation times (typically $0.5 \mathrm{~h}, 1 \mathrm{~h}, 2 \mathrm{~h}$ ).

2. Eliminate nonphagocytized bacteria either by centrifugation (cells in suspension; $7 \mathrm{~min}$ at $340 \times \mathfrak{g}$ ) or by elimination of the medium (adherent cells).

3. Reincubate infected cells during $45-60 \mathrm{~min}\left(37^{\circ} \mathrm{C} ; \mathrm{CO}_{2}\right.$ incubator) in cell culture medium (without serum) containing gentamicin at high concentration (typically 50-100 times the minimal inhibitory concentration (MIC) for the bacterial strain used $[12,19])$ in order to eliminate nonphagocytized bacteria that may adhere to the cell surface ( see Note 5).

4. Wash three times with PBS at room temperature to eliminate bacterial debris and gentamicin.

5. Collect infected cells in $1 \mathrm{~mL}$ of sterile water in order to lyse them and allow for release of phagocytized bacteria. 
6. Prepare logarithmic dilutions of the cell lysates in PBS and plate $50 \mu \mathrm{L}$ on TSA or any other appropriate agar plate; proceed to colony counting after $24 \mathrm{~h}$ incubation.

7. In parallel, determine protein content of the cell lysates by the Folin-Ciocalteu method [30], using a commercial kit or the method described in Note 1.

8. Express the data as $\mathrm{CFU} / \mathrm{mg}$ of cell protein and select for further experiments the conditions for which you obtain approximately $10^{6} \mathrm{CFU} / \mathrm{mg}$ cell protein (see Note 6).

\subsection{Intracellular Growth}

1. Reincubate the infected cells in cell culture medium supplemented with $10 \%$ fetal calf serum. For control conditions, add gentamicin at a concentration close to the MIC (as measured in the culture medium used for the experiment) to avoid extracellular growth (Fig. 2) and, in case of cell killing, release of a small
A.

influence of inoculum
and incubation time
on phagocytosis

$P$. aeruginosa $\mathrm{PAO} 1$

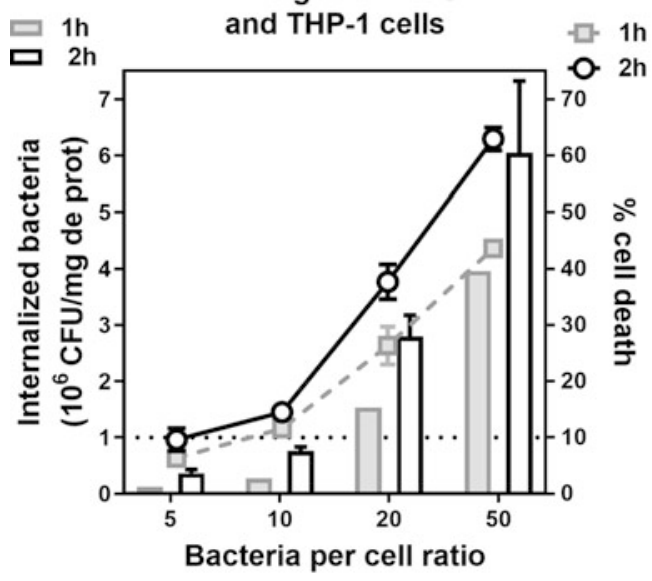

\begin{tabular}{c} 
B. $\begin{array}{c}\text { influence of gentamicin concentration } \\
\text { in the culture medium on extracellular } \\
\text { contamination }\end{array}$ \\
\hline
\end{tabular}

S. aureus ATCC 25923 and THP-1 cells

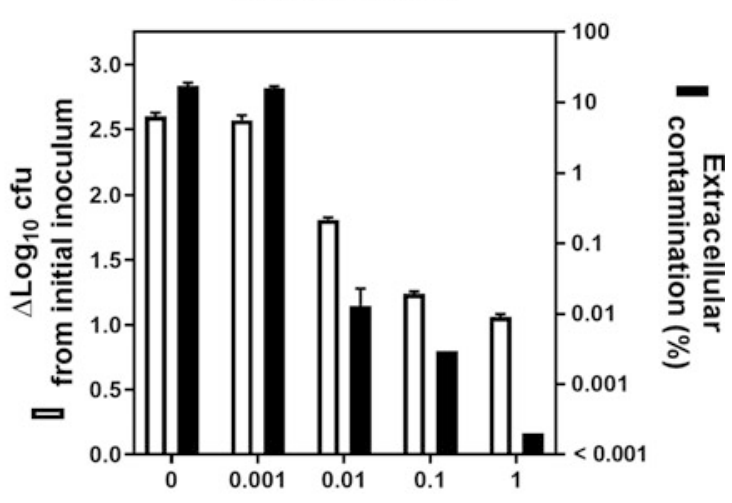

Gentamicin extracell. conc. (x MIC)

Fig. 2 Setting up a model of intracellular infection. (a) Determination of the optimal bacterial inoculum and phagocytosis time, as exemplified for $P$. aeruginosa PA01 (adapted from [12]). Cells were incubated for 1 or $2 \mathrm{~h}$ with PA01 at increasing bacteria-to-cell ratios (left axis). The percentage of mortality of THP-1 cells was assessed at the end of the phagocytosis period (right axis). Data for $1 \mathrm{~h}$ : gray symbols and bars; data for $2 \mathrm{~h}$ : open symbols and bars; the back bar and black dot correspond to the conditions considered as optimal for this model (dotted line: $10^{6} \mathrm{CFU} / \mathrm{mg}$ protein with $<10 \%$ cell toxicity). (b) Determination of the optimal concentration of gentamicin to add to culture medium of controls during incubation to avoid extracellular contamination, as exemplified for $S$. aureus ATCC25923 (adapted from [19]). Left axis: change in intracellular inoculum (log scale) after $24 \mathrm{~h}$ of incubation of infected cells in the presence of increasing concentrations of gentamicin (expressed in multiples of the MIC. Right axis: percentage of contamination of the extracellular medium in these conditions as assessed by the counting of colonies after plating of pooled culture fluids and washing media (limit of detection: $0.001 \%$ ) 


\subsection{Assessment of Antibiotic Intracellular Activity}

number of bacteria into the medium [19]. For experimental conditions, add the antibiotic you wish to test at the appropriate concentration in the culture medium (see Notes 7 and 8).

2. At the end of the incubation period, wash the cells three times in PBS and collect them in sterile distilled water as explained above (Subheading 3.4). Proceed to plating, CFU counting and protein assay.

The model described here allows to monitor antibiotic activity against intracellular bacteria over time or as a function of the extracellular concentration of the antibiotic (Fig. 3) [12, 19].

1. Considering time effects, bacterial growth is often delayed inside the cells (lag phase of a few hours), so that bacterial killing by antibiotics occurs slower than in broth. Moreover, the rate of bacterial killing by antibiotics is often biphasic, with

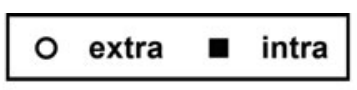

A. S. aureus ATCC 25923

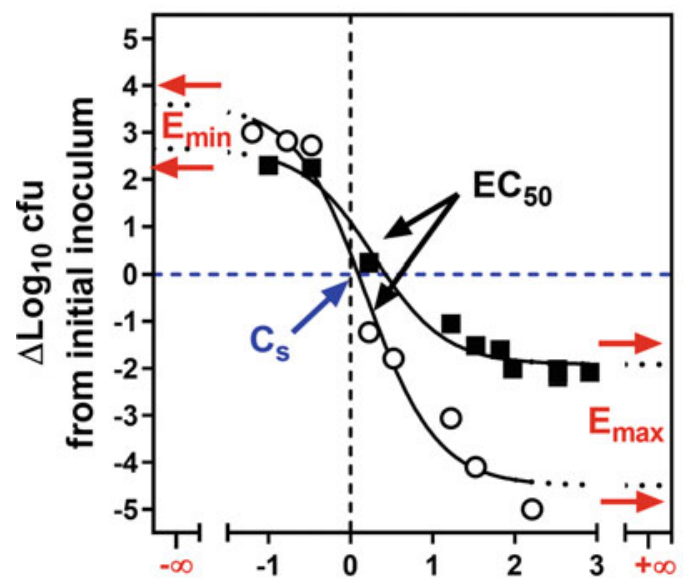

B. P. aeruginosa PAO1

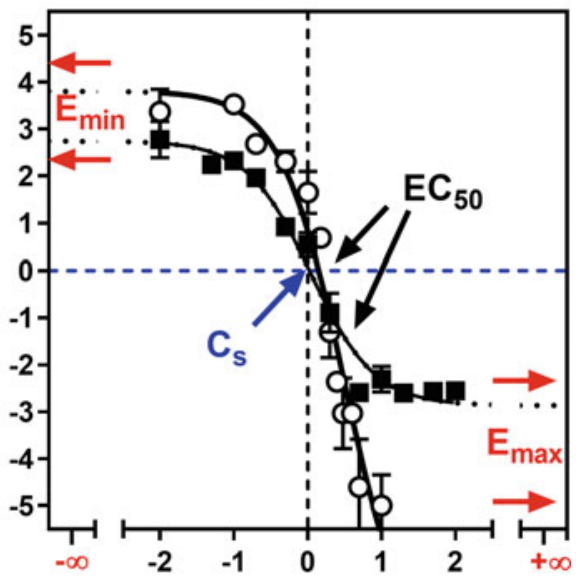

$\Delta \log _{10}$ cfu from initial inoculum (X MIC)

Fig. 3 Concentration-effect relationship for the extracellular and intracellular activity of antibiotics, exemplified for moxifloxacin against $S$. aureus (a) and $P$. aeruginosa (b). Comparison of the activity of moxifloxacin after $24 \mathrm{~h}$ incubation with moxifloxacin in broth (extracellular activity; open symbols) or in infected THP-1 cells (closed symbols). The ordinate shows the change in the number of CFU per $\mathrm{mL}$ (extracellular) or per $\mathrm{mg}$ cell protein (intracellular) compared to the postphagocytosis inoculum (blue horizontal line at 0 ). The abscissa shows the antibiotic concentration expressed as the $\log _{10}$ of its MIC in broth. The dotted line shows the MIC value. Data are used to fit Hill equations (slope factor $=1$ ) and derive the pertinent key pharmacodynamic parameters, namely (1) $E_{\min }$ (change in CFU for an infinitely low antibiotic concentration; in red); (2) $E_{\max }$ (relative efficacy; maximal reduction in inoculum as extrapolated for an infinitely large concentration, in $\log _{10}$ CFU units compared to the original inoculum; in red); (3) $\mathrm{EC}_{50}$ (relative potency; concentration causing a reduction of the inoculum halfway between $E_{\min }$ and $E_{\max }$, in black); (4) $C_{\mathrm{s}}$ (static concentration; concentration resulting in no apparent bacterial growth; in blue). Constructed based on data presented in $[12,15]$ 
a first rapid drop in the number of CFUs, followed by a slower killing, which can even correspond to a plateau (no further decrease in CFUs). This is one of the hallmarks of persisters (Fig. 4).

2. Considering concentration effects, performing experiments with broad ranges of extracellular concentrations (from sub-MIC values to many times the MIC) allows obtaining full concentration-response curves for fitting with sigmoid regressions (Fig. 3).

3. Using the corresponding Hill's equation, key pharmacological descriptors of activity can be calculated.

(a) The relative minimal efficacy ( $E_{\min }$; in $\log _{10}$ CFU units), that is, the increase in the number of CFU for an infinitely low antibiotic concentration compared to the original postphagocytosis inoculum.

(b) The relative maximal efficacy ( $E_{\max }$; in $\log _{10}$ CFU units), that is, the decrease in the number of CFU for an infinitely large concentration of antibiotic.

(c) The relative potency $\left(\mathrm{EC}_{50}\right.$; in $\mathrm{mg} / \mathrm{L}$ or in multiples of MIC), that is, the concentration of antibiotic yielding a response half-way between $E_{\min }$ and $E_{\max }$.

(d) The static concentration $\left(C_{s}\right.$; in $\mathrm{mg} / \mathrm{L}$ or in multiple of MIC), that is, the concentration of antibiotic resulting in no apparent bacterial growth compared to the original inoculum [15].

4. Three major observations have been made with this type of model (Figs. 3 and 4).

(a) First, the relative minimal efficacy is in general similar in the extracellular and intracellular models for facultative intracellular bacteria. Intracellular $E_{\min }$ should be considered as an "apparent" intracellular value, because in this case, the presence of extracellular bacteria that are not killed in the medium by subinhibitory concentrations of antibiotic cannot be excluded.

(b) Second, the static concentration against intracellular bacteria (i.e., the antibiotic concentration preventing bacterial growth) is in most cases close to the MIC, suggesting that the potency of the drug is not directly correlated with its accumulation inside the cells, possibly because of poor intracellular bioavailability. The molecular reasons for this loss of potency inside the cells still remain to be established.

(c) Third, the antibiotic maximal efficacy is in most cases much lower against intracellular bacteria than against extracellular bacteria, suggesting poor bacterial 


\section{oxacillin clarithromycin $\mathbf{\nabla}$ moxifloxacin}

A Intracellular time kill curve

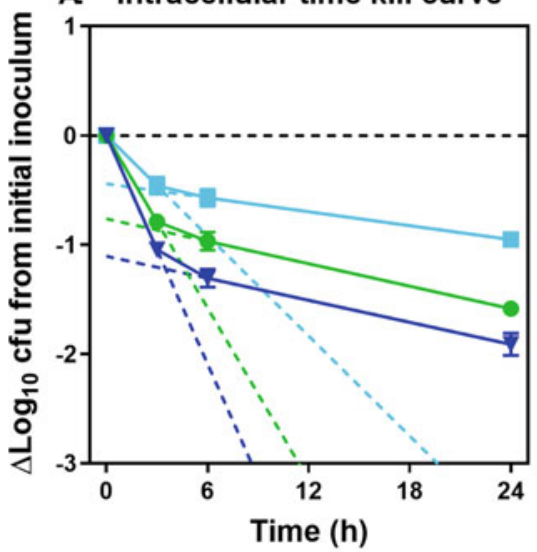

B. Intracellular conc.-response curve

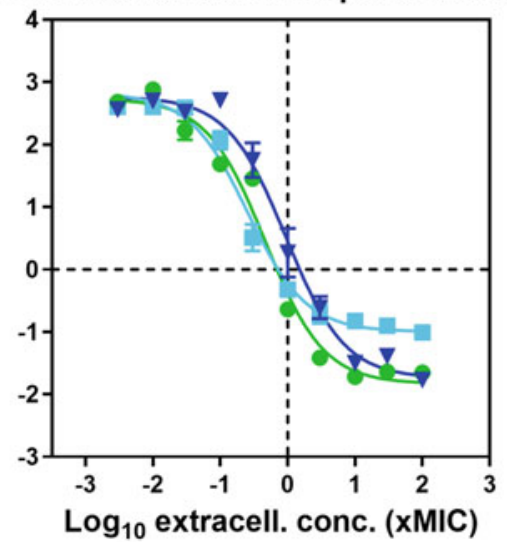

C. GFP fluorescence in intracellular survivors to oxacillin
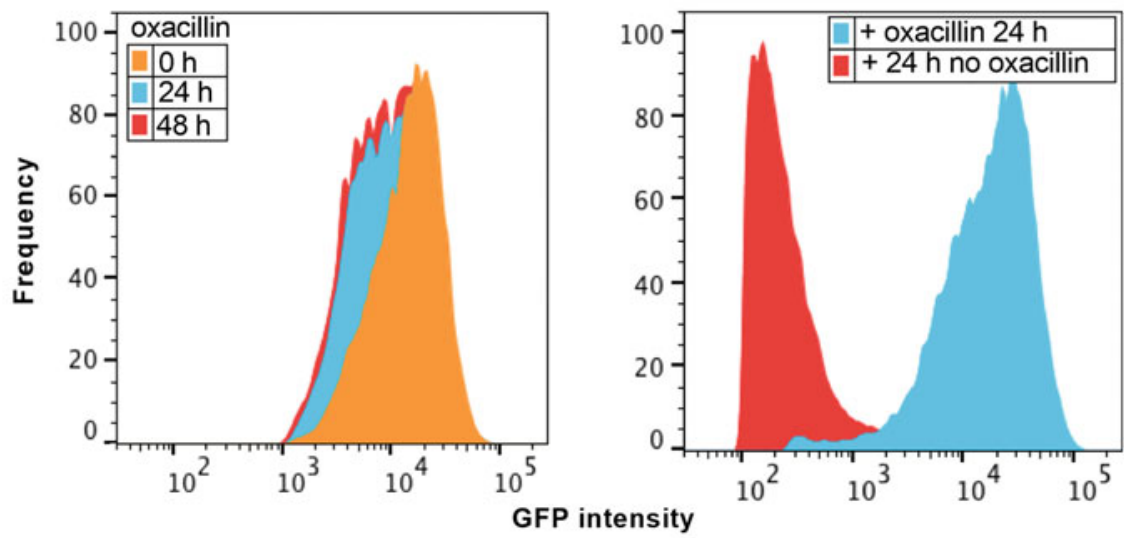

GFP intensity

- low persister fraction $\quad$ high persister fraction
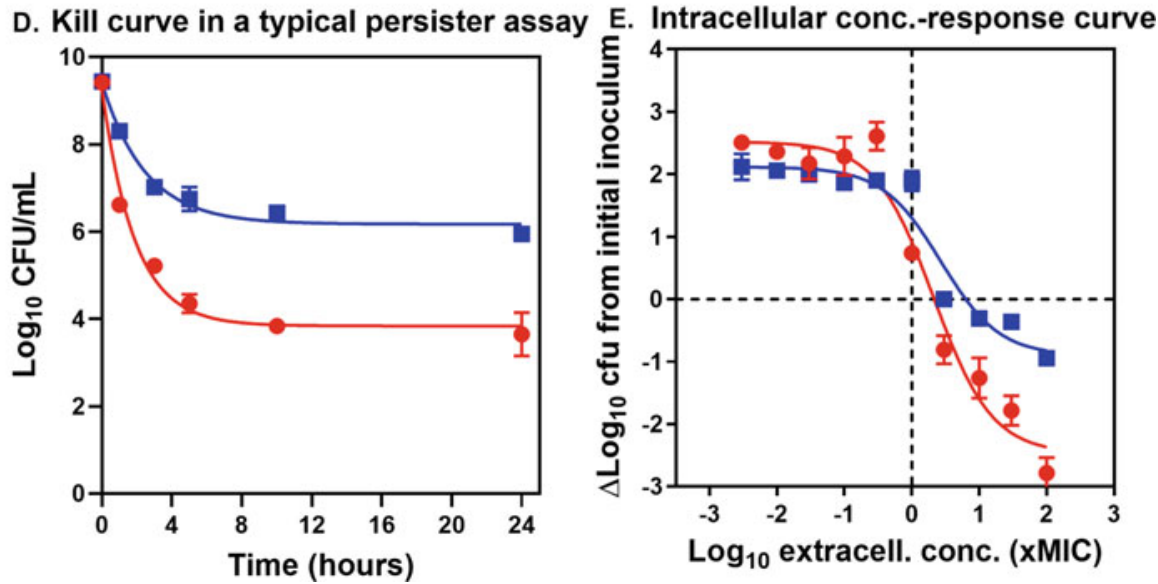

Fig. 4 Demonstration of intracellular persisters in $S$. aureus upon exposure to antibiotics at high concentrations. (a) Time-kill curves of $S$. aureus SH1000 in J774 mouse macrophages incubated with oxacillin, 
responsiveness to antibiotic action in the intracellular environment. By means of a fluorescence dilution technique (described in Chapter 18), this has been recently ascribed for $S$. aureus to the fact that intracellular survivors have adopted a persister phenotype, characterized by a nondividing state, and reversible in permissive cells as soon as the antibiotic pressure is relieved [18]. The $E_{\max }$ value differs from one antibiotic to the other against a same strain, but may differ from one strain to the other with a same antibiotic. These discrepancies could find their explanation in the capacity of different antibiotics or strains to generate persisters [35]. Again the reasons for these differences need to be established.

\section{Notes}

1. Protein assay can be performed without any commercial kit, using the protocol described by Lowry [30]. Reagents required are Biuret reagent (extemporaneous mixture of $100 \mathrm{~mL} 2 \%$ $\mathrm{Na}_{2} \mathrm{CO}_{3}, 1 \mathrm{~mL} 2 \%$ potassium sodium tartrate, $1 \mathrm{~mL} 1 \%$ $\mathrm{CuSO}_{4} .5 \mathrm{H}_{2} \mathrm{O}$ ), $2 \mathrm{~N}$ Folin-Ciocalteu reagent (diluted to $1 \mathrm{~N}), 1 \mathrm{~N} \mathrm{NaOH}$, and a standard $(100 \mu \mathrm{g} / \mathrm{mL}$ bovine albu$\mathrm{min}$ ). In brief, incubate $0.5 \mathrm{~mL}$ of cell lysate (or dilution thereof), blank (medium in which cells were collected), water (solvent of albumin standard) or albumin standard during 30-120 min with $0.5 \mathrm{~mL} 1 \mathrm{~N} \mathrm{NaOH}$. Subsequently, add

Fig. 4 (continued) clarithromycin, or moxifloxacin at 50× their respective MIC. The graph shows the biphasic killing rate, with a fast killing during the first $3 \mathrm{~h}$ and a slower killing thereafter (highlighted by dotted lines). The equation of these linear relationships allows to calculate a minimum duration of killing (MDK) for $90 \%$ of the population comprised between 2.9 and $6.6 \mathrm{~h}$ for the first phase but longer than $24 \mathrm{~h}$ for the second phase (adapted from [18]). (b) Concentration-response curves for the same antibiotics after $24 \mathrm{~h}$ of incubation of infected cells. A plateau is reached corresponding to a maximal reduction of $1-1.8 \log _{10}$ CFU from the postphagocytosis, depending on the drug (adapted from [18]). (c) Flow cytometric profiles of the frequency of events as a function of GFP intensity over time for samples collected from an experiment similar to that described in panel $\mathbf{b}$ and incubated $0 \mathrm{~h}$ (postphagocytosis), $24 \mathrm{~h}$, or $48 \mathrm{~h}$ with $50 \times$ the MIC of oxacillin (left) or $24 \mathrm{~h}$ with oxacillin then reincubated for $24 \mathrm{~h}$ in the absence of antibiotic (right). Cells were infected by SH1000 transformed by a plasmid expressing GFP under the control of an inducible promoter. The inducer is added during the prephagocytosis cultures only. Once the bacteria have been internalized, any dilution of the fluorescence signal can be interpreted as denoting bacterial division (adapted from [18]). (d) Time-kill curve of extracellular bacteria in stationary cultures exposed to moxifloxacin at $100 \times$ its MIC to calculate their persister fraction. The graph compares two clinical isolates harboring low (red) and high (blue) persister fractions (adapted from [35]). (e) Concentration-response curves for the same isolates in an intracellular model of infected THP-1 human monocytes incubated during $24 \mathrm{~h}$ with moxifloxacin. The graph shows that the $E_{\max }$ of moxifloxacin is higher (more negative) for the isolate harboring the lower persister fraction in stationary-phase culture (adapted from [35]) 
$5 \mathrm{~mL}$ of Biuret reagent and incubate for $10-20 \mathrm{~min}$. Next, add $0.5 \mathrm{ml}$ of $1 \mathrm{~N}$ Folin reagent to each tube and read absorbance at $660 \mathrm{~nm}$ after $30 \mathrm{~min}$ of incubation (the last step needs to be done tube by tube and with a timer; incubation time should be strictly the same for each tube). The concentration of proteins in the sample is then calculated as ( $\left[\mathrm{OD}_{\text {sample }}-\mathrm{OD}_{\text {blank }}\right] /$ $\left.\left[\mathrm{OD}_{\text {standard }}-\mathrm{DO}_{\text {water }}\right]\right) \times 100 \mu \mathrm{g} / \mathrm{mL}$ [standard concentration] $\times$ dilution factor) [3].

2. Viability can be easily assessed using a trypan blue exclusion test (vital colorant excluded from viable cells). To this effect, add $100 \mu \mathrm{L}$ of cell suspension to $900 \mu \mathrm{L}$ of trypan blue reagent, incubate for $10 \mathrm{~min}$ at $37^{\circ} \mathrm{C}$ and determine the proportion of dead cells (colored in blue) by cell counting using a haemocytometer. An alternative method consists of measuring the release of $\mathrm{LDH}$, a cytosolic enzyme, in the supernatant of a cell culture, which occurs upon permeabilization of the cell membrane. $\mathrm{LDH}$ viability kits are commercially available. The assay can also be performed using the method of Vassault [32], which measures the consumption of NADH upon reduction of pyruvate in lactate by LDH (Fig. 5 ).

In brief, mix $50 \mu \mathrm{L}$ of culture medium or $10 \mu \mathrm{L}$ of cell lysate with $2.5 \mathrm{~mL}$ of $0.244 \mathrm{mM}$ NADH solution in Tris buffer $(81.3 \mathrm{mM}$ Tris, $203.3 \mathrm{mM} \mathrm{NaCl}$ ). Add $500 \mu \mathrm{L}$ of $9.76 \mathrm{mM}$ natrium pyruvate (prepared in the same buffer) and follow $\mathrm{NADH}$ consumption by measuring optical density at $339 \mathrm{~nm}$ immediately and then every min during $5 \mathrm{~min}$. Cell mortality is evaluated by the ratio between $\mathrm{LDH}$ activity in the supernatant (estimated by $\left[\mathrm{OD}_{0} \mathrm{~min}-\mathrm{OD}_{5} \mathrm{~min}\right] / \mu \mathrm{L}$ of medium $\times$ total volume of the culture medium) and the total activity in the culture (sum of total activity in supernatant and total activity in cell lysate estimated as $\left(\left[\mathrm{OD}_{0}\right.\right.$ min $\left.-\mathrm{OD}_{5} \mathrm{~min}\right] / \mu \mathrm{L}$ of medium $\times$ total volume of cell lysate) $)$.

3. When using obligatory or facultative intracellular organisms which are specifically equipped to use the serum complement to increase phagocytosis, opsonization causes massive infection of the cells [36]. Preopsonization is therefore not systematically required [37] and, alternatively, culture medium could be supplemented with decomplemented serum or calf serum (heated for $30 \mathrm{~min}$ at $56^{\circ} \mathrm{C}[38]$ ) to reduce phagocytosis in order to reach postphagocytosis inocula compatible with maintenance of cell viability for $24 \mathrm{~h}$.<smiles>CC(=O)C(=O)[O-]</smiles>

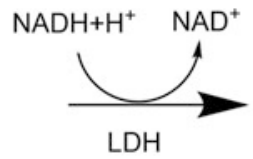<smiles>CC(O)C(=O)[O-]</smiles>

Fig. 5 Conversion of pyruvate to lactate by lactate dehydrogenase (LDH) 
4. The number of eukaryotic cells to use depends on the virulence of the bacterial strain. For cytotoxic bacterial strains or species, use a higher eukaryotic cell number in order to keep enough cells after phagocytosis, as some killing may occur during this step [12].

5. A limitation of this assay is that the strain has to be susceptible to gentamicin. This antibiotic is selected for the elimination of nonphagocytized bacteria because it is rapidly bactericidal while at the same time entering only very slowly inside eukaryotic cells. It is therefore important to test for the susceptibility of the bacterial strain to gentamicin (MIC determination) before starting the experiment. Use of lysostaphin as a lytic agent for some extracellular bacteria ( $S$. aureus) is also proposed in the literature but we showed that it enters inside the cells and may thus affect intracellular viability [33].

6. Depending on the virulence of the strain and its capacity to multiply intracellularly, it is important to check in parallel for the viability of the cells at the end of the phagocytosis period as well as at the end of the experiment. To this effect, a viability assay (trypan blue exclusion assay or LDH release assay, see Note 2) should be run in parallel and the postphagocytosis inoculum should be selected so as to guarantee cell viability.

7. Antibiotics or antibacterial agents (or even their solvent if not soluble in water) may also be toxic to eukaryotic cells. Again, it is important to check for cell viability in the presence of the tested agent for correct interpretation of the data. Massive cell death induced by the antibacterial agent can trigger bacterial release into the culture medium and therefore lead to the evaluation of the activity of the tested agent against extracellular bacteria rather than against intracellular bacteria [39].

8. For highly bactericidal antibiotics, check that the amount of carried-over antibiotic does not impair bacterial growth on the plates [33]. This can be done by comparing the number of CFU on plates from lysates preexposed or not to $12.5 \mathrm{mg} / \mathrm{L}$ charcoal (adsorbing residual antibiotic) during $10 \mathrm{~min}$ [20] or by plating bacteria on agar supplemented with $0.4 \%$ charcoal [13].

\section{Acknowledgments}

Intracellular infection models have been developed thanks to the financial support of the Belgian Fonds National de la Recherche Scientifique, the Interuniversity Attraction Poles initiated by the Belgian Science Policy Office, and the Brussels and Walloon Regions. 


\section{References}

1. Garzoni C, Kelley WL (2011) Return of the Trojan horse: intracellular phenotype switching and immune evasion by Staphylococcus aureus. EMBO Mol Med 3:115-117

2. Anderson GG, Martin SM, Hultgren SJ (2004) Host subversion by formation of intracellular bacterial communities in the urinary tract. Microbes Infect 6:1094-1101

3. Cossart P, Sansonetti PJ (2004) Bacterial invasion: the paradigms of enteroinvasive pathogens. Science 304:242-248

4. Mehlitz A, Rudel T (2013) Modulation of host signaling and cellular responses by Chlamydia. Cell Commun Signal 11:90

5. Rohde M, Chhatwal GS (2013) Adherence and invasion of streptococci to eukaryotic cells and their role in disease pathogenesis. Curr Top Microbiol Immunol 368:83-110

6. Alder KD, Lee I, Munger AM, Kwon HK et al (2020) Intracellular Staphylococcus aureus in bone and joint infections: a mechanism of disease recurrence, inflammation, and bone and cartilage destruction. Bone 141:115568

7. Del Mar CM, Torrents E (2020) Differential adaptability between reference strains and clinical isolates of Pseudomonas aeruginosa into the lung epithelium intracellular lifestyle. Virulence 11:862-876

8. Adams KN, Takaki K, Connolly LE et al (2011) Drug tolerance in replicating mycobacteria mediated by a macrophage-induced efflux mechanism. Cell 145:39-53

9. Helaine S, Cheverton AM, Watson KG et al (2014) Internalization of Salmonella by macrophages induces formation of nonreplicating persisters. Science 343:204-208

10. Carryn S, Chanteux H, Seral C et al (2003) Intracellular pharmacodynamics of antibiotics. Infect Dis Clin N Am 17:615-634

11. Van Bambeke F, Barcia-Macay M, Lemaire S, Tulkens PM (2006) Cellular pharmacodynamics and pharmacokinetics of antibiotics: current views and perspectives. Curr Opin Drug Discov Devel 9:218-230

12. Buyck JM, Tulkens PM, Van Bambeke F (2013) Pharmacodynamic evaluation of the intracellular activity of antibiotics towards Pseudomonas aeruginosa $\mathrm{PAOl}$ in a model of THP-1 human monocytes. Antimicrob Agents Chemother 57:2310-2318

13. Chalhoub H, Harding SV, Tulkens PM, Van Bambeke F (2019) Influence of $\mathrm{pH}$ on the activity of finafloxacin against extracellular and intracellular Burkholderia thailandensis, Yersinia pseudotuberculosis and Francisella philomiragia and on its cellular pharmacokinetics in THP-1 monocytes. Clin Microbiol Infect 26:1254.el-1254.e8

14. Lemaire S, Kosowska-Shick K, Appelbaum PC et al (2010) Cellular pharmacodynamics of the novel biaryloxazolidinone radezolid: studies with infected phagocytic and nonphagocytic cells, using Staphylococcus aureus, Staphylococcus epidermidis, Listeria monocytogenes, and Legionella pneumophila. Antimicrob Agents Chemother 54:2549-2559

15. Lemaire S, Kosowska-Shick K, Appelbaum PC et al (2011) Activity of moxifloxacin against intracellular community-acquired methicillinresistant Staphylococcus aureus: comparison with clindamycin, linezolid and co-trimoxazole and attempt at defining an intracellular susceptibility breakpoint. J Antimicrob Chemother 66:596-607

16. Lemaire S, Glupczynski Y, Duval Vet al (2009) Activities of ceftobiprole and other cephalosporins against extracellular and intracellular (THP-1 macrophages and keratinocytes) forms of methicillin-susceptible and methicillin-resistant Staphylococcus aureus. Antimicrob Agents Chemother 53:2289-2297

17. Lemaire S, Olivier A, Van Bambeke F et al (2008) Restoration of susceptibility of intracellular methicillin-resistant Staphylococcus aureus to beta-lactams: comparison of strains, cells, and antibiotics. Antimicrob Agents Chemother 52:2797-2805

18. Peyrusson F, Varet H, Nguyen TK et al (2020) Intracellular Staphylococcus aureus persisters upon antibiotic exposure. Nat Commun $11: 2200$

19. Barcia-Macay M, Seral C, Mingeot-Leclercq MP et al (2006) Pharmacodynamic evaluation of the intracellular activities of antibiotics against Staphylococcus aureus in a model of THP-1 macrophages. Antimicrob Agents Chemother 50:841-851

20. Lemaire $S$, Tulkens PM, Van Bambeke F (2011) Contrasting effects of acidic $\mathrm{pH}$ on the extracellular and intracellular activities of the anti-gram-positive fluoroquinolones moxifloxacin and delafloxacin against Staphylococcus aureus. Antimicrob Agents Chemother 55:649-658

21. Lemaire S, Van Bambeke F, Appelbaum PC, Tulkens PM (2009) Cellular pharmacokinetics and intracellular activity of torezolid (TR-700): studies with human macrophage (THP-1) and endothelial (HUVEC) cell lines. J Antimicrob Chemother 64:1035-1043 
22. Lemaire S, Van Bambeke F, Tulkens PM (2009) Cellular accumulation and pharmacodynamic evaluation of the intracellular activity of CEM-101, a novel fluoroketolide, against Staphylococcus aureus, Listeria monocytogenes, and Legionella pneumophila in human THP-1 macrophages. Antimicrob Agents Chemother 53:3734-3743

23. Melard A, Garcia LG, Das D et al (2013) Activity of ceftaroline against extracellular (broth) and intracellular (THP-1 monocytes) forms of methicillin-resistant Staphylococcus aureus: comparison with vancomycin, linezolid and daptomycin. J Antimicrob Chemother 68:648-658

24. Peyrusson F, Butler D, Tulkens PM, Van Bambeke F (2015) Cellular pharmacokinetics and intracellular activity of the novel peptide deformylase inhibitor GSKI322322 against Staphylococcus aureus laboratory and clinical strains with various resistance phenotypes: studies with human THP-1 monocytes and J774 murine macrophages. Antimicrob Agents Chemother 59:5747-5760

25. Peyrusson F, Tulkens PM, Van Bambeke F (2018) Cellular pharmacokinetics and intracellular activity of gepotidacin against Staphylococcus aureus isolates with different resistance phenotypes in models of cultured phagocytic cells. Antimicrob Agents Chemother 62: e02245-e02217

26. Peyrusson F, Van Wessem A, Dieppois G et al (2020) Cellular pharmacokinetics and intracellular activity of the bacterial fatty acid synthesis inhibitor, afabicin desphosphono against different resistance phenotypes of Staphylococcus aureus in models of cultured phagocytic cells. Int J Antimicrob Agents 55:105848

27. Sandberg A, Jensen KS, Baudoux $P$ et al (2010) Intra- and extracellular activities of dicloxacillin against Staphylococcus aureus in vivo and in vitro. Antimicrob Agents Chemother 54:2391-2400

28. Sandberg A, Jensen KS, Baudoux P et al (2010) Intra- and extracellular activity of linezolid against Staphylococcus aureus in vivo and in vitro. J Antimicrob Chemother 65:962-973

29. U.S. Department of Health and Human Services (2009) Biosafety in microbiological and biomedical laboratories, vol 5. Available via https://www.cdc.gov/labs/pdf/CDC-Bio safetymicrobiologicalBiomedicalLaboratories2009-P.pdf. Accessed 6 Oct 2020

30. Lowry OH, Rosebrough AL, Farr AL, Randall RJ (1951) Protein measurement with the Folin phenol reagent. J Biol Chem 193:265-275
31. Strober W (2001) Trypan blue exclusion test of cell viability. Curr Protoc Immunol Appendix 3:Appendix 3B

32. Vassault A (1987) Lactate dehydrogenase. In: Bergemeyer HU (ed) Methods in enzymatic analysis, vol III: enzyme I oxydoreductases, transferases. VHC Publishers, Veinheim

33. Seral C, Van Bambeke F, Tulkens PM (2003) Quantitative analysis of gentamicin, azithromycin, telithromycin, ciprofloxacin, moxifloxacin, and oritavancin (LY333328) activities against intracellular Staphylococcus aureus in mouse J774 macrophages. Antimicrob Agents Chemother 47:2283-2292

34. Garcia LG, Lemaire S, Kahl BC et al (2012) Influence of the protein kinase $\mathrm{C}$ activator phorbol myristate acetate on the intracellular activity of antibiotics against hemin- and menadioneauxotrophic small-colony variant mutants of Staphylococcus aureus and their wild-type parental strain in human THP-1 cells. Antimicrob Agents Chemother 56:6166-6174

35. Nguyen TK, Peyrusson F, Dodémont $M$ et al (2020) The persister character of clinical isolates of Staphylococcus aureus contributes to faster evolution to resistance and higher survival in THP-1 monocytes: a study with moxifloxacin. Front Microbiol 11:587364

36. Drevets DA, Campbell PA (1991) Roles of complement and complement receptor type 3 in phagocytosis of Listeria monocytogenes by inflammatory mouse peritoneal macrophages. Infect Immun 59:2645-2652

37. Seral C, Carryn S, Tulkens PM, Van Bambeke F (2003) Influence of P-glycoprotein and MRP efflux pump inhibitors on the intracellular activity of azithromycin and ciprofloxacin in macrophages infected by Listeria monocytogenes or Staphylococcus aureus. J Antimicrob Chemother 51:1167-1173

38. Carryn S, Van Bambeke F, Mingeot-Leclercq MP, Tulkens PM (2002) Comparative intracellular (THP-1 macrophage) and extracellular activities of beta-lactams, azithromycin, gentamicin, and fluoroquinolones against Listeria monocytogenes at clinically relevant concentrations. Antimicrob Agents Chemother 46:2095-2103

39. Lemaire $S$, Bogdanovitch T, Chavez-Bueno $S$ et al (2006) Bactericidal activity of ceragenin CSA-13 against intracellular MSSA, hospitalacquired (HA) and Community-acquired (CA) MRSA, and VISA in THP-1 macrophages: relation to cellular toxicity ? Poster presented at the 46th Interscience Conference on Antimicrobial Agents and Chemotherapy, San Francisco, USA, 27-30 Sept 2006 